\title{
UNIVERSITYOF
}

FORWARD

THINKING

WESTMINSTER用

WestminsterResearch

http://www.westminster.ac.uk/westminsterresearch

Prospects in Britain in the light of the Bus Services Act 2017

White, $\mathbf{P}$.

This is an accepted manuscript of an article published by Taylor \& Francis in Research in Transportation Economics, 69, pp. 337-343.

The final definitive version is available online:

https://dx.doi.org/10.1016/j.retrec.2018.03.003

(C) 2018 Taylor \& Francis

The WestminsterResearch online digital archive at the University of Westminster aims to make the research output of the University available to a wider audience. Copyright and Moral Rights remain with the authors and/or copyright owners.

Whilst further distribution of specific materials from within this archive is forbidden, you may freely distribute the URL of WestminsterResearch: ((http://westminsterresearch.wmin.ac.uk/).

In case of abuse or copyright appearing without permission e-mail repository@westminster.ac.uk 


\section{Prospects in Britain in the light of the Bus Services Act}

\section{Historical background}

\subsection{The express coach experience}

Under the Transport Act of 1980, express coach services in Britain were 'deregulated', removing controls on pricing, capacity and route licensing, although quality controls on operators were strengthened. The outcomes were generally regarded as successful in terms of stimulating ridership, lower fares and service innovations. Subsequent changes in other European countries such as Norway, Sweden, France and Germany can be seen as implementing similar policies, also with positive outcomes. A review of the British case is provided by White and Robbins (2012). It is noteworthy, however, that despite apparent ease of entry by smaller operators, the main competition is inter-modal (with rail and car), and clearly dominant operators have emerged within the coach sector. While in the British case this largely represents a continued role of the previous major operator (National Express), it is striking that consolidation has occurred very quickly in some other countries, notably the role of Flixbus in the German and French markets.

No changes are proposed in this respect, although the lack of data in the British case (operators are not required to submit ridership data to the government) ironically makes it more difficult to describe effects with the precision possible in other European countries. The 1980 Act also introduced some liberalisation of local bus service regulation, but with limited effects, apart from removal of fares controls.

Note that the term 'Britain' is used to refer the mainland comprising England, Wales and Scotland. The 'United Kingdom' also encompasses Northern Ireland, in which a more restrictive regulatory system has been retained, and most services are operated by a stateowned operator. Islands such as the Isle of Man and Channel Isles fall neither in the UK nor the EU, enabling some experiments in the regulatory frameworks to take place (notably in Jersey), within a similar bus operating culture.

\subsection{The Transport Act of 1985}

The Transport Act of 1985 introduced much more radical changes in the local bus market, including removal of route licensing, replaced by a simple registration system in which the operators determined which services they would run commercially, setting route, timetable and fares. Local authorities were given powers to provide services under contract. In most cases these filled gaps in the commercially-registered network, both spatial (such as lowdensity rural routes), and temporal (such as evening and Sunday journeys over routes on which commercial services operate daytime Mon-Sat). About $80 \%$ of the network has been operated 'commercially' on this basis, rising in recent years as local authorities have cut back support due to overall budget constraints.

Most of the contracts are on a 'net cost' basis, i.e. the bidder takes both cost and revenue risk. In such cases, the contracting authority generally specifies route, timetable and fares to be charged, but the operator may retain revenue above the forecast level, thus incentivising higher service quality and marketing efforts. Many cases also occur where an operator may 'deregister' a commercial service, having decided it is no longer viable. Where the local authority wishes to retain a contracted service over the same route, the incumbent has a 
marked advantage in bidding for 'net cost' contracts, since it has knowledge of the revenue generated. Conversely, other operators who may have lower total costs may be unwilling to bid (or make a very cautious revenue assumption, resulting in a higher net bid). No requirement was imposed on the deregistering incumbent operator to disclose such data. This issue was highlighted in a paper at Thredbo 3 in 1993 (White and Tough 1993, 1995), and also in the Competition Commission's report on the bus industry (2011).

Within London, similar deregulation had been proposed initially, but was later dropped for a variety of reasons (Torode 2015). Instead, a system of competitive contracting within a planned network developed, also described as 'franchising'.

\subsection{Main outcomes of the Transport Act 1985}

The main outcomes of the 1985 Act, which came into effect on 26 October 1986, may be split into two phases:

1. From $1985 / 86$ to $1999 / 2000$. A very sharp fall in unit costs per bus-kilometre was observed, of about $45 \%$ in real terms, both in London and elsewhere. This was associated with reductions in staffing (notably in management and engineering functions), higher driver productivity, lower wage rates and worse conditions for staff, a 'flattening out' of peak: interpeak service levels, and use of smaller vehicles. Some costs were transferred to local authorities, including aspects of passenger information, which may have resulted in a slight overstatement of operating cost reduction as such: however, these are included in published data for total public expenditure associated with bus service provision. Total bus-km run expanded strongly, but ridership fell, associated in part with higher fares as result of reduced subsidies (especially in some large metropolitan areas outside London), but also fare increases in general. Average load per bus outside London fell sharply, largely offsetting lower operating costs per bus-km to give a broadly stable cost per passenger trip. Within London, broadly stable service levels and ridership resulted in similar average loads being carried, hence cost per passenger trip falling approximately in line with cost per bus-km (White 2017).

2. From $2000 / 01$ to date. Unit costs per bus-km have risen substantially from their low point in 1999/2000 (albeit still below 1985/86 in real terms). It has been necessary to raise wages and improve working conditions to attract sufficient staff, especially in high cost areas. An extensive study of the local bus industry by KPMG for the DfT (2016, page 26 ) indicates a $21 \%$ rise in bus driver weekly real earnings between 2000 and 2013. Productivity in terms of bus-km per member of staff has remained broadly stable (KPMG 2016, figure 9) between 2004/05 and 2013/14, in contrast to the improvement shown during the first phase: 'one off' savings in the earlier phase cannot be repeated, and increased congestion now requires more buses and drivers to be provided to attain a given service level and capacity. However, overall ridership trends have been more positive, notably due to extension of free travel to all older users (aged about 60 upward) since 2006 in England (earlier in Wales and Scotland), which now accounts for about one-third of all ridership. Operators have paid more attention to service quality and marketing. London displayed very strong growth in both bus-km and ridership. However, public expenditure has risen sharply, due to 
increased compensation payments to operators for free travel by older people, and higher service levels in London.

In addition to endogenous factors, ridership has been affected by exogenous variables, notably growing car ownership outside London, and population growth within London. A very low car ownership level may be observed in London - 308 cars per 1,000 population compared with 488 nationally (DfT 2017f). Most recently, the broadly stable total ridership trend since the mid-2000s (London's growth offsetting decline elsewhere) has been reversed, with drops in London as well. Growing congestion and taxi/private hire car competition are probably major factors.

\section{Competition Policy}

A marked feature of the 1985 Act was the application of competition policy to the bus industry. Previously, co-ordination of services had been encouraged - for example, scheduling twenty-minute headways by two operators over the same route to give a tenminute headway, and/or use of a common fare scale and ticket products. Many examples existed of 'joint services' on which two or more operators provided such co-ordination. The development of off-bus ticketing from the 1970s was also associated with this, a common travelcard permitting use of all (or most) operators' services in the same area. This helped to reduce boarding times and remove the financial penalties of interchange. At the time the 1985 Act came into force, competition policy was handled through two bodies, the Office of Fair Trading (OFT) which made initial investigations, and the Monopolies Commission which undertook major investigations after referral from the OFT. The Monopolies Commission was later replaced by the Competition Commission. Subsequently, both this and the OFT were merged into the present Competition and Markets Authority (C\&MA) in 2014. Application of competition policy rules to the bus industry, especially following its strengthening under the Competition Act 1998, was comprehensively described by TAS (2001).

The aims of competition policy as applied to the local bus industry could be seen as meeting several different objectives:

- Stimulating competition for service contracts, enabling authorities concerned to reduce costs and/or improve service quality through a range of bidders rather than a single incumbent operator being the only option available (sometimes described as 'competition for the market'). This might encourage some innovation in working methods, but not necessarily in pricing or service quality except when initiated by the contracting authority. This aspect is generally non-controversial, except in respect of possible worsening in earnings and working conditions for staff. Its effectiveness may be limited by the revenue risk imposed in 'net cost' contracts, and also the ability of new operators to secure operating bases, especially in urban areas with high land values. The route-level contracting within London is the most extensive example. The passenger rail industry in Britain can also be seen as a major example, albeit with very much larger contract sizes which limits the range of possible bidders, but with greater scope for the bidder to put forward innovations in service levels, pricing and marketing.

- Stimulating direct competition between different operators for the same customers, often described as 'on the road' or 'in the market' competition. In the case of bus services this would imply two or more operators competing over all or part of the same route, on factors such as fares, frequency, vehicle quality, etc. The 1985 Act 
permitted this in all areas outside London within mainland Britain, but the actual extent has been much more limited.

- Stimulating innovation. Measures to reduce costs might stimulate innovations such as more efficient scheduling, lower overhead costs, etc. Passenger-focussed innovation might include better marketing, higher quality vehicles, improved information, etc. However, the discouragement of inter-operator ticketing in the earlier phases of competition policy may have had the reverse effect, encouraging a reversion by passengers to cash-paid tickets where more than one operator served the same route (so they could board the first bus to arrive), thus increasing dwell times at stops. Ironically, it may be easier to introduce co-ordinated ticketing and pricing systems where one operator absorbs others in the same area, rather than through voluntary co-operation between operators which otherwise remain able to compete (for example, for tendered work).

A further aspect of competition policy relates to the lack of fares control under the 1985 Act. Given low short-run price elasticity (of around -0.4), it is possible for a dominant operator to increase fares (and thus revenue) substantially, despite losses of consumer surplus and ridership that result. In theory, competition should emerge to combat this, but its extent has often been patchy. In some cases, operators which have pursued such fare policies may have changed them in the light of poor user reactions, as reflected in the 'Value for Money' indicator assessed in surveys by Transport Focus, rather than any substantial competition (White 2014, White 2017).

Two other important issues also apply to competition policy:

- Is it applied to a particular mode of transport, or between modes? The application of competition policy to the bus industry has focussed almost wholly within that mode for example, the major Competition Commission enquiry (2011) specifically excluded taxis, railways and other modes as competitors. However, it can be argued that express coach deregulation, for example, was far more effective in stimulating intermodal competition (especially with rail) than between coach operators as such. Likewise, growth in competition from taxis has been of growing importance for local buses. It is noteworthy that in assessing the award of rail franchises in the North of England in 2015 (Trans-Pennine Express to First Group, and Northern Rail to Arriva) the C\&MA was concerned that the same groups operated bus services in the areas covered, resulting in a review into such effects after the rail franchises had been awarded and put in place. Eventually, these issues were found to be negligible except for a few services (Forster 2016).

- The timescale on which investigations take place. For example, if a merger is deemed potentially anti-competitive, it is clearly desirable to assess this prior to a merger actually being implemented, but in some cases this has taken place later - for example, Stagecoach and Preston Bus (Competition Commission 2009), or the rail franchise awards mentioned above. This may result in considerable delay, or disruption (for example where divestment is required).

\section{Measuring market shares and associated effects}

A further question is that of how market shares are measured. DfT policy in the local bus industry has been to regard named operator ridership and revenue data as commercially confidential, and this is only published in aggregated form by region. Operator market shares 
are then defined as those of registered bus trips per week in the area concerned, which may only crudely approximate to ridership, especially if smaller vehicles are used by some operators. Making use of this DfT indicator, the KPMG study (2016, figure 24) examined the degree of concentration (using a Herfindahl index), graphed against bus trip rate per head of population. No clear relationship was found, and no examples with both a low index value and high per capita bus usage (note that a low degree of concentration may not necessarily indicate extensive 'head to head' competition, but rather a network split between numerous operators in the same region, each serving different routes or areas).

Taking some examples for 2015-16 data (DfT 2016c), it can be seen that in some cases, very high concentration can be found - for example, in North East Lincolnshire (the urban area including Grimsby and Cleethorpes) Stagecoach - one of the largest five companies, which dominate the British bus market (Competition Commission 2011) had a market share of $99.7 \%$ on this basis (much of the remaining $0.3 \%$ was accounted for by one independent operator, whose principal scheduled service, on re-tendering, subsequently passed to Stagecoach). In the administrative county of Lincolnshire itself, the Stagecoach share was $54.2 \%$, but the second largest operator, Essential Fleet Services (with a share of $18.8 \%$ ) was almost wholly an operator of rural demand-responsive minibus services, most unlikely to represent a pro rata share of ridership. In the case of Greater Manchester, Stagecoach had a share of $42.2 \%$ and First one of $39.7 \%$, reflecting broadly similar shares of operation within that conurbation. However, in this case, a figure for Stagecoach ridership is in the public domain, of 111 million passenger trips in 2015-16 (Passenger Transport 2016), corresponding to a share of about 54\% of the DfT all-operator figure of 205 million (DfT $2016 \mathrm{~b}$ ). This is consistent with earlier evidence of Stagecoach pursuing lower fares and a more positive marketing strategy in that conurbation (White 2014).

It should also be noted that a high concentration does not necessarily indicate user dissatisfaction - for example, a Transport Focus survey in N E Lincs indicates generally high satisfaction with Stagecoach services there (Transport Focus 2016).

The unsatisfactory nature of registered bus trips or bus-km based indicators was acknowledged by DfT (2017a, page 31), although no specific alternative was proposed, and it has been explicitly retained in the response to consultations published in September 2017 (DfT 2017b), in relation to defining operator market shares for purposes of operator objections to proposed Enhanced Partnerships (see section 7.3 below). A somewhat surprising comment in the latter (pages $37 / 38$ ) is that ".... no 'independent' [DfT's own quotation marks] patronage data could be called upon......" for this indicator, since the DfT itself is relating on operator-reported data to aggregate passenger trip totals by area.

\section{Partnership working}

Although competition was generally encouraged, the benefits of partnership working between local authorities and operators began to be recognised, principally in cases where the local authority assisted through provision of facilities such as bus priorities, bus shelters and accessible kerbside stops, and the operator responded by improving its offer through new vehicles, better marketing and passenger information, enhanced driver training, etc. Many such schemes developed, known as 'quality partnerships' (QPs), often on an informal basis, with positive effects on ridership (TAS 1997, 2001). However, any arrangements involving partnerships between operators remained very difficult under competition rules. 


\section{Changes under the 2000 and 2008 Acts}

The Transport Act of 2000 [hereinafter the '2000 Act'], and Local Transport Act 2008 [hereinafter the '2008 Act'] introduced a number of changes to the Transport Act of 1985, albeit with fairly limited effect in practice. Given the better performance in London to 2000 in terms of ridership, it was already argued that such an option might give beneficial results elsewhere, typically in other large conurbations which had suffered a marked decline in ridership. Provisions of the 2000 Act enabled such changes to be introduced, but under very restrictive conditions, and in the end no schemes were put forward under such powers. The 2000 Act may have had a much greater effect on the bus industry through establishing a mandatory national minimum standard for concessionary fares for older and disabled users (initially half the adult fare), which later formed the basis for the free travel scheme. It also introduced powers for a workplace parking levy (WPL, applied in Nottingham) and congestion charging (applied in London). Local Transport Authorities were required to provide five-year bus strategies as a component of Local Transport Plans (LTPs).

The 2000 Act also firmed up the quality partnership concept by introducing the concept of 'Statutory Quality Partnerships' (SQPs) in which formal arrangements apply, and authorities are able to specify minimum standards for operators and vehicles using them which may be higher than the national legal minimum (for example, the 'euro' engine emissions level). Operators are then granted access to the facilities provided (typically, bus priorities) and operators not meeting such standards excluded. In practice, only a few of these have been set up (for example, in the city centres of Birmingham and Nottingham) and most partnerships continued on a less formal basis. The 2008 Act had wider effects, through enabling partnership arrangements which would previously have fallen foul of competition regulations. These included joint timetabling, and common ticketing. A noteworthy example is Oxford, where a desire from local politicians to reduce the number of buses operating in the environmentally-sensitive central area was attained without offsetting disbenefits to passengers, through a voluntary partnership agreement, under which co-ordinated headways and common off-bus ticketing was introduced on major corridors. It also widened scope of existing partnerships which had developed in many areas.

The 2008 Act included powers to enable London-style contracting (or 'franchising') somewhat easier, under the 'Quality Contract' concept. However, the only, substantial attempt to introduce this was in Tyne \& Wear (a conurbation of about 1.5 million people, centred on Newcastle and Sunderland). The North East Combined Authority (NECA) put forward a scheme in October 2014. This was strongly opposed by the principal groups operating in the area (Stagecoach and Go Ahead). Hearings were held on the proposals in summer 2015. The proposals were then reviewed by a 'Quality Contract Scheme Board' under the provisions of the Act (a three-person panel). This concluded that the proposed scheme had failed three of the five tests applicable (Local Transport Today 2015). Issues raised by the Board included:

- Lack of robust economic assessment of overall costs and benefits, especially on effects of risks borne by the contracting authority

- Limited quality and quantity of data on which to make such an assessment, in the absence of obligations on operators to make this available

- The impacts on incumbent operators displaced, especially in terms of profits lost. Perhaps surprisingly, the panel concluded that compensation should be payable in 
such cases (a possible paradox arises in that some of the profits being made would fall within the 'excessive' levels defined in the 2011 Competition Commission enquiry. Also, had such profit margins been eroded by 'on the road' competition as envisaged in the 1985 Act, no compensation issue would have arisen).

A further issue in relation to operator profitability is not only the fact that the Competition Commission identified excessive levels in some areas, but also that such levels may help to strengthen the financial position of the larger groups which also operate in less profitable areas. Hence, the loss of more profitable operations in some large urban areas that might switch to franchising could affect prospects for service elsewhere (Higginson 2016).

An underlying issue is the extent to which better performance in London may be replicated elsewhere, due to specific local factors. It may be argued that, at least by default, it forms a 'control' case against which deregulation can be assessed. On this basis Preston (2018) indicates generally superior performance in London when applying a counterfactual case: demand in London grew substantially more than in the counterfactual, while falling substantially elsewhere, vis a vis some expected growth in the counterfactual. Welfare changes indicate a large growth in producer surplus in both regions (associated with radical reductions in operating costs), but consumer surplus rose strongly in London whilst generally falling sharply (dependent on assumptions made) elsewhere. Overall a net positive welfare change per capita was produced, but very much larger in London.

\section{Background to the Bus Services Bill 2016}

he introduction of the Bill, especially its 'franchising' powers, may have come as something of a surprise to the bus operating industry. Whereas the 2000 and 2008 Acts had been introduced under a Labour government, the 2016 Bill was introduced by the Conservative government elected in 2015. An important factor may have been the desire to give greater powers to CAs covering major conurbations in England outside London, which were then in process of being formed. In parallel with the deregulation of bus services in 1986, the metropolitan counties had been abolished earlier that year, reducing the scope for comprehensive planning in major conurbations. Creation of the Greater London Authority in 2000 restored such a structure in London (albeit limited to the boundary of the former GLC), but a vacuum existed elsewhere. In particular, there was interest in the prospective CA for Greater Manchester having bus powers. Some of the initiative seems to have come from the Treasury, rather than the Department of Transport as such, which was associated with the role of the then Chancellor of the Exchequer, George Osborne, who represented a constituency close to Manchester, and put forward such proposals (Passenger Transport 2015). In the event, this became a critical feature in the timescale of the Act, whose passage was required in order to give powers to Mayors standing for election in CAs in early May 2017.

There was a wider appreciation of the need for more comprehensive partnership powers, reducing the scope for competition policy to inhibit positive changes. The Competition Commission enquiry of 2011 had also raised some issues requiring legislative change, notably the asymmetry of information available to bidders for tendered services.

The 'Buses Bill' was announced in the Queen's Speech in May 2015, although not introduced in Parliament until the following year. A series of 'Bus Reform Workshops' was held by the DfT in autumn 2015, enabling issues to be explored with interested parties. Note 
that many sections of the Act are themselves modifications and/or insertions to parts of previous Acts, notably those of 1985 and 2000. For example, section 1 of the 2017 Act inserts new sections (113C to 1130 ) into the 1985 Act.

It is also the case that the wording in the 2017 Act left many aspects to be determined by the Secretary of State, through Guidance or Secondary Legislation. For example, in section 9 (inserting a new section 138F into the $2017 \mathrm{Act}$ ) notice of a proposal to make a plan for an Enhanced Partnership (EP) may only be given if a 'sufficient' number of operators affected do not object, but the definition of 'sufficient' is not shown within the Act itself, being shown within later draft secondary legislation. While the Act received Royal Assent on 27 April 2017, the Guidance existed only in draft form for consultation (DfT 2017a). The response to the consultation was published in September 2017 (DfT 2017b). This summarises the views of respondents, and indicates the actions the DfT proposes to take. In most cases, the Department does not indicate to change the initial proposals, although some minor changes are envisaged - for example, to amend regulation 2 of the Franchising Schemes (Service Permits) (England) to enable authorities to award 'short notice' service permits.

Subsequently, final guidance has been produced for Franchising (DfT 2017d), Enhanced Partnerships (DfT 2017e), and Advanced Quality Partnerships (DfT 2018), along with some secondary legislation. However, guidance and secondary legislation related to open data may not be finalised for some time.

The final version of the Act was generally similar to the initial Bill, except for the addition of powers relating to improved information for passengers with disabilities, and an independent auditor for franchise proposals. Some changes were introduced in both Lords and Commons, for example removing the restrictions on new municipal bus operators being set up, and empowering authorities other than CAs with elected mayors to implement franchising without consent from the Secretary of State. These were reversed through actions by the government using its majority in later stages of the Act's passage.

The changes set out in the 2017 Act apply almost exclusively to England, and not at all to Scotland. The Scottish Government is currently consulting on possible changes, some of which have fairly close parallels in the 2017 Act, re partnerships and simpler procedures for introducing franchising. The Welsh Government is considering powers to enable franchising, and also those which would make it easier for new municipal operators to be set up, possibly of assistance where there is lack of competitive bidding for tendered services. Interestingly, the C\&MA has expressed support for such a concept, were it to have that effect (Local Transport Today 2017).

\section{Principal changes introduced by the Bus Services Act 2017}

\subsection{Franchising schemes}

The franchising powers (section 4, inserting new sections 123A to 123X into the $2000 \mathrm{Act}$ ) make the process of introducing this change much easier than in the 2000 or 2008 Acts, although the term 'contracting' might be a better description in practice. The contracting authority may specify the pattern of services to be provided, along with fares charged (including all types of ticket, technology to be used, etc.). All services within the defined area would be provided under contract, apart from those under service permits issued by the same authority (following the London Service Permit [LSP] system found in London, administered by TfL, which grants permits for cross-border services such as commuter 
coaches, and specialised services within Greater London, such as those for tourists or schools). However, considerable discretion exists as to the type of contracting pattern adopted, which would not necessarily follow the route-level system used in London.

Incumbent operators displaced by franchising would not be entitled to receive compensation for loss of profits (thus resolving an issue raised in the Tyne \& Wear review). However, their existing assets such as depots or vehicles could not be subject to compulsory purchase.

A scheme may be set up by a single authority, or two or more authorities acting together (section 123A), covering either the whole or part of its/their area (in contrast to London, where the franchise area is coterminous with the Greater London boundary).

A period of notice of six months is to be provided when an authority determines to set up a franchise scheme (section $123 \mathrm{H}$ ), having carried out the required consultation, through publishing a summary consultation document, the business case and supporting materials, and an assurance report by an independent auditor who in turn may receive guidance from the Secretary of State (section 123D). It is noteworthy that it may cancel such an agreement with the same notice period - for example due to financial difficulties (section 123N).

A striking feature is that CAs with directly-elected mayors (of which six are now in place, two Labour and four Conservative) are empowered to introduce franchising without further consent being required from the Secretary of State (section 123A), although the independent auditor must be satisfied as to the soundness of the proposals. However other authorities are required to obtain consent of the Secretary of State. This is a somewhat debatable approach - the existence of an elected CA Mayor is no guarantee of professional expertise in network planning, which might be a more relevant test to apply.

Services within a franchising scheme may only be provided under contracts or permits, apart from those under section 22 of the 1985 Act - essentially, schemes run by voluntary organisations, normally using small vehicles, but open to the general public (section 123J): this also applies within AQPs (below). There is a requirement to facilitate the role of small and medium sized operators in the provision of local services (section 123G).

Section 5 of the 2017 Act (inserting new section 143A into the 2000 Act) requires operators to provide relevant information when an authority is preparing a scheme, such as passenger journeys, revenue, and vehicle-km operated, for a period of up to five years before the demand is made.

It is of interest to note that the final guidance (DfT 2017e, paragraphs 4.52-4.53) envisages, in respect of rural areas, possible use of franchising powers to "...balance-out the provision of services across the area, potentially diverting some service from more urban areas, where the authority may consider that there is over-provision of services, to rural areas.......". This is a very sharp contrast with the rationale underlying the 1985 Act (re the case against crosssubsidy).

\subsection{Advanced Quality Partnerships (AQPs)}

Advanced Partnership Schemes supersede existing SQPs, all SQPs automatically becoming AQPs, and new schemes may be set up on this basis. In contrast to SQPs, physical facilities are not necessarily a requirement to be met by the local authorities, but alternative measures may be provided, such as changes in parking policy which may benefit bus services. A scheme may be set up by one or more Local Transport Authorities (LTAs), who are given 
powers regarding maximum fares that may be charged by operators, and the frequency and timing of services. However, these are subject to there being "....no admissible objections....from relevant operators" [section 113E (7)]. Services not meeting specified standards may be excluded [section 113J]. A scheme would run for a minimum of five years but may be revoked, with agreement of all operators, before that date (DfT 2018). The scheme may include requirements about operators selling multi-operator tickets as well as their own, provision of smart ticketing, passenger information, and how services are publicised (for example, using a single a marketing name for all services in the partnership area). A maximum fare may also be set for a particular route (perhaps reflecting previous cases where lack of fares control resulted in some very high fares, see section 2 above), but there are no powers to control other fares.

\subsection{Enhanced Partnerships (EPs)}

These may be seen as an intermediate level between AQPs and franchising. LTAs gain wider powers than under AQPs, under sections 9 to 15 of the 2017 Act, notably over frequency and timing of services (by introducing new section $138 \mathrm{C}(1)$ to the $2000 \mathrm{Act}$ ). Bus improvement objectives may be set. Regulations may also be set out regarding the emission standards of vehicles, appearance of vehicles [subsection (4)(f)] and the pricing of multioperator tickets [subsection $(4)(h)$ ]. These regulations then form requirements for route registrations, which may then be monitored for compliance. From the passengers' point of view, something similar to an integrated network may be set up in terms of ticketing and brand image, without proceeding to franchising as such. In contrast to AQPs, more extensive powers over ticketing include those to require all operators to follow the same set of zones for fares and tickets; follow common rules (such as period of validity for travelcards, and age eligibility for youth tickets) and charging a set price for a multi-operator or multi-modal ticket.

The LTA must prepare a plan for an EP, setting out the content of a scheme [section $138 \mathrm{H}$ ], and a date from which it is to come into effect. There is provision for revocation of a scheme, which could be automatic if targets are not met (DfT 2017c, paragraph 8.22). LTAs may require information from operators when an EP plan is being prepared [section 10, inserting new section 143B into the $2000 \mathrm{Act}$, although these are less explicit than in respect of franchising. An important aspect of EPs is that service registration powers and responsibilities will transfer from the Traffic Commissioners to the LTA in question where services fall wholly within the designated EP area [section 14, inserting new section $6 \mathrm{G}$ into the 1985 Act].

\subsection{Other components of the 2017 Act}

In contrast to the permissive powers described above, other sections of the 2017 Act are mandatory, applying over the whole of mainland Britain (sections 17) or within England only (sections 18 to 22 ).

\subsubsection{Accessible information for bus passengers}

Section 17 of the 2017 Act introduces a new section 181 into the Equality Act 2010 regarding information for bus passengers, to be specified by the Secretary of State, notably provision of audible and visual displays, which may be of particular benefit to users with disabilities. This issue was raised by many speakers in debates on the Bill in both Lords and Commons. There is, for example, a desire in many areas to have the level of information provided on TfL services, which features visual display of the name of the next stop, the 
ultimate destination of the service, and audible announcements. Responsibility for compliance rests with the Traffic Commissioners. Regulations - to be set by Ministers could specify the outcome required, but not the precise technology, which would be left to discretion of operators. Tracking of buses by GPS is now very widespread, and provided to users by some larger groups such as Arriva through mobile phone apps, so extending it to on-bus information should not be too difficult.

\subsubsection{Information about bus services}

While operators have been required to register services since the 1985 Act, they have been free to determine fares. Information for passengers is often very variable. Section 18 inserts a new section $141 \mathrm{~A}$ into the $2000 \mathrm{Act}$, which requires operators, LTAs and Traffic Commissioners in England to provide information as specified by regulations set out by the Secretary of State. This includes information about route, stopping places, timetables, fares and tickets. Under sub-section (4)(a) 'live' (real time) information about vehicle location may also be specified, and 'information about the operation of the services in the past'. The last part may help to resolve problems where Traffic Commissioners have sought to investigate service reliability, but roadside manual observation is often limited to a small sample. Where the operator uses real-time systems, such stored data gives a much more comprehensive picture, but issues have arisen in the past as to whether the operator is the 'owner' of such data and thus not obliged to disclose it.

\subsubsection{Variation or cancellation of a service registration}

As mentioned in section 1.2 of this paper, a problem has arisen for many years in that an incumbent may gain an advantage when tendering to replace a service which they themselves have deregistered. Under section 19 of the 2017 Act, inserting a new section 6C into the 1985 Act, an operator in England cancelling or reducing a service may be required to provide data on the number of passengers carried, fares paid and total revenue to the LTA, with a 14-day pre-notification period (prior to the 56-day registration with the Traffic Commissioners). This will enable the LTA to provide such data to other bidders for a replacement service, stimulating wider competition in tendering.

\subsubsection{Municipal operation}

The deregulation and privatisation processes in local bus services in Britain did not coincide. Privatisation of publicly-owned operators was gradual process, and some ten remain under the ownership of local authorities in urban areas, notably Lothian (Edinburgh area) and Nottingham, although further sales to the private sector have continued - most recently, that of Thamesdown (Swindon area) to the Go Ahead Group. A number of these operators perform very well in retention or growth of ridership, and service quality ratings. They operate as 'arms' length' businesses, not under direct political control of their owning authorities, and not able to receive general subsidies (they receive compensation for concessionary passenger trips, and may tender for services on the same basis as other operators). However, they do not necessarily aim to achieve the same profit margins as the larger private groups and may, for example, provide better levels of evening and Sunday services. Some commentators, such as Transport for Quality of Life (2015), have advocated an expansion of such operators. In some areas, LTAs are having difficulty securing bids for tendered services, and a publicly-owned operator could fill this gap, and/or act as a comparator for private sector bidders. 
It was therefore perhaps surprising that the original Bill included powers to prevent the formation of new operators of this type. This was strongly opposed in readings of the Bill, and a majority vote in the Lords removed this provision. However, the government restored the original powers, now enacted as section 22 of the 2017 Act. While it may be argued that it would be inappropriate for a local authority-owned company to be a bidder for contracts under a franchise scheme in the same area, it is unclear why such a wide-ranging power was needed for this purpose. As in the case of rail franchising, it is ironic that publicly-owned operators from other countries (notably RATP Dev as an urban operator) are able to contract for services, but not those in Britain itself.

\section{Competition policy implications}

The new Act changes the emphasis from previous policy in respect of competition, and this was a matter of concern to the C\&MA, expressed in an open public letter in February 2016 (C\&MA 2016a). A subsequent letter in June 2016 to the Minister responsible for the Bill, Andrew Jones, made available via the DfT website, reiterated such concerns (C\&MA 2016b), notably the potential benefits of local on-road competition as outlined in the 2011 Competition Commission report, and concerns re franchising. A subsequent reply from the Minister (DfT 2016a) indicated that these had been largely accepted in the progress of the then Bill. These included the assessment of the impacts of franchising arrangements, the role of the C\&MA as a statutory consultee on the introduction of franchising schemes, competition in allocation of routes and slots, ability of operators to set their own ticket prices with multi-operator ticketing schemes, and other aspects. The involvement of the C\&MA as a statutory consultee in the introduction of franchising schemes should prevent some of the timescale problems found in previous enquiries as discussed in section 2.

\section{Possible effects of the 2017 Act}

The mandatory powers in the Act remedy a number of deficiencies that have been evident in the deregulated framework for some years, notably in provision of information to passengers, and from incumbent operators to LTAs to assist effective tendering.

The permissive powers to establish AQPs and EPs enable benefits of greater co-ordination to be provided to passengers, notably in ticketing, but without the full complexity of franchising. However, the continued role of single-operator tickets could result in somewhat complex fare structures still existing. The extent to which the full franchising powers will be implemented remains to be seen. A survey of a sample of senior managers within the industry favoured either the existing deregulated framework (plus partnerships) or full contracts (with risk on authority), rather than some intermediate concession/franchise models as specified in the survey (CILT 2016). It is noteworthy that some groups not part of the traditional British operating industry appear much happier with franchising provisions, being familiar with such systems elsewhere (notably HCT Group, Tower Transit of Australia, and Abellio of the Netherlands).

An interesting example of franchising may be found in Jersey, where the state government has made a contract with a single operator (LibertyBus, a subsidiary of HCT Group) for the whole network. This provides for much greater operator involvement in network design and marketing than in the London system, for example, and very positive results have been reported in terms of reduced public spending of $£ 800,000$ p.a., and growth in ridership of a 
third in three years (HCT and States of Jersey 2016), although an independent assessment has not yet been carried out.

A major factor is that local authorities will have no more financial resources than now indeed, further cuts in central government funding have resulted is large cuts in tendered services in many areas (in some, complete elimination). The lack of funding may deter experimentation with franchising schemes, for example.

It is also the case that more urgent issues affecting the industry are not addressed directly by the Act, notably growing congestion in many areas, affecting service speed, quality and costs. Growing taxi and private hire vehicle competition is also considered to be a major factor.

\section{Research needs arising from implementation of the Act}

While it is clearly too early to talk of measurable impacts of the Act, it is opportune to identify the data requirements likely to arise in making meaningful analyses of its outcomes. A distinction may be drawn between changes that may be applied universally (disclosure of revenue and ridership information to operators bidding for a tendered service, open data and passenger information), and those who application is permissive.

Much of the data required is already collected as part of routine work by the DfT, such as ridership bus-km run, revenue, etc. However, the local authority administrative areas used to classify such data may not be appropriate where a scheme covers differently-defined areas. Such data will also be needed for periods prior to scheme implementation, as the Act's powers already envisage for scheme preparation - for example, five years in the case of franchising schemes. Control cases may be desirable. especially where some types of scheme may be implemented in only a few cases (which may arise with franchising). Background contextual data will also be required - as in evident in the London case, very different trends in car ownership and population growth have been important. Such context would also include the 'measures' introduced under AQPs.

Another feature may be the need to disaggregate existing data series in greater depth. For example, total bus-km run in an area run gives no indication of its distribution by time period. The much higher evening and weekend service levels in London are noteworthy, and implementation of franchising may produce similar outcomes elsewhere: guidance to the Act envisages possible improvements in night and weekend services (DfT 2017e, page 7).

Fares data currently collected by DfT is reported at a highly aggregated level, and more local level of reporting may be desirable, for example, to determine impacts of powers to set maximum fares. A shift to more integrated ticketing may also stimulate off-bus purchase, speeding up boarding times.

User perception may also be important. Transport Focus conducts very extensive surveys, but it would be desirable to ensure that areas sampled include those within which changes are introduced under the Act, including a 'before' period. User perception of common 'branding' as in AQPs could also be assessed.

More problematic are those measures which are not introduced in clearly-defined areas, such as the requirements for data disclosure when services are deregistered. This problem is known to exist, but its distribution is highly uncertain. If areas can be identified in which 
greater data disclosure in introduced, changes in the average number of bids per contract (which might be expected to increase) would be an appropriate indicator.

Financial outcomes are also important. Local authority expenditure may be increased, or reduced (for example, if a franchising scheme enabled cross-subsidy of loss-making services which are now tendered separately). Operating profits may also change (reducing 'excessive' profits in some areas could result in a transfer of producer surplus to consumers, but with effects on overall viability of large groups also operating elsewhere). These could be combined with the indicators affecting passengers to develop comprehensive welfare assessments, on the lines of previous studies reported by Preston (2018).

\section{Conclusions}

The 2017 Act clearly reflects a substantial change in thinking by the British government, shifting from a perhaps somewhat extreme emphasis on competition as a policy aim, to one with a greater emphasis on partnership and potential for franchising. As such, it may bring British policy closer to that of other countries which have adopted contracting but without 'on the road' competition (for example, in Scandinavia). Much of this can be seen as a response to practical experience, notably difficulties in co-ordination of services, and of introducing franchising under earlier powers. Many of the detailed legal issues may be seen as unique to Britain, but when the opportunity arises to assess eventual outcomes comparisons may be drawn with experience elsewhere. It is also opportune to identify data requirements for such assessments to be made.

After thirty years of argument about 'London $v$ the rest' a properly-monitored franchise experiment should enable more constructive debate in future.

\section{References}

Chartered Institute of Logistics and Transport [CILT] (2016) Bus and Coach Forum 'Bus reform: survey of senior directors of local bus service operators' Summary of Findings, June.

Competition and Markets Authority (2016a) 'Competition, Co-operation and partnership working' Open letter to Local Transport Authorities, 29 February, 5pp.

Competition and Markets Authority (2016b) Letter to Andrew Jones, MP (Parliamentary Under Secretary of State for Transport), 29 June

Competition Commission (2009) A report on the completed acquisition by Stagecoach Group plc of Preston Bus Limited, 11 November

Competition Commission (2011) Local Bus Services Market Investigation: a report on the supply of local bus services in the UK (excluding Northern Ireland and London), 20 December, London

Department for Transport (2016a) Open letter to the C\&MA Acting Chief Executive regarding its recommendations on the Bus Services Bill, October.

Department for Transport (2016b) Table Bus 0109a 'Passenger journeys on local bus services by local authority: England, from 2009/10' 
Department for Transport (2016c) Table 1001b 'Operator Market Share of weekly bus trips by local authority: England, October 2016/January 2016

Department for Transport (2017a) 'Bus Services Bill: Consultation on Draft Regulations and Guidance', February

Department for Transport (2017b) 'Bus Services Act 2017: Response to the Consultation on Draft Regulations and Guidance', September

Department for Transport (2017c) 'The Bus Services Act 2017: Enhanced Partnerships Guidance, December

Department for Transport (2017d) 'The Bus Services Act 2017: Franchising Scheme Guidance, December

Department for Transport (2017e) The Bus Services Act 2017: New powers and opportunities, November

Department for Transport (2017f) Transport Statistics Great Britain 2017, table 0906

Department for Transport (2018) 'The Bus Services Act 2017: Advanced Quality

Partnerships Schemes Guidance, January

Forster, A. (2016) 'Operators Challenge CMA probe into North's public transport' Local Transport Today, 5 August, page 8

HCT Group and States of Jersey (2016) 'Practical bus franchising: the Jersey model' (16pp) Higginson, Martin (2016) 'Cross subsidy and franchising/contracting' in ALBUM supplement to Passenger Transport 29 April 2016, pp 22-25

KPMG (2016) Local Bus Market Study: Report to Department for Transport, January, London.

Local Transport Today (2015) 13 November, pages 1, 4-7

Local Transport Today (2017) 15 September, page 14

Passenger Transport (2015) 22 May, page 3

Passenger Transport (2016) 11 November, page 18

Preston, John (2018) The impact of regulatory reform on public transport markets, chapter 8 (pp 121-140) in Cowie, J and Ison, S (eds) The Routledge Handbook of Transport Economics, Routledge, London and New York.

TAS Partnership Ltd. (1997) The Bus in a New Era: Partnerships for the Future - conference programme and papers, March

TAS Partnership Ltd. (2001) Quality Bus Partnerships: Good Practice Guide, Version 03.05.01, May, Preston.

Torode, Roger (2015) Privatising London's Buses. Capital Transport Publishing Ltd., chapter 7

Transport for Quality of Life (2016) ‘Building a world-class bus system for Britain’, January 
Transport Focus (2016) Bus Passenger Survey Autumn 2015 report, pp 50, 51 \& 135

Van der Veer, J.P. (2002) 'Entry deterrence and quality provision in the local bus market' Transport Reviews, Vol 22, no 3 (July - September), pp 247-265.

White, Peter and Tough, Stephen $(1993,1995)$ 'Alternative Tendering Systems and Deregulation in Britain' in Love, Jean (ed) Proceedings of the Third International Conference on Competition and Ownership on Surface Passenger Transport ['Thredbo3'] September 1993, pp283-299; and in revised form in Journal of Transport Economics and Policy, Vol XXIX, no 3, September 1995, pp 275-289

White, P. (2014) 'An assessment of the Competition Commission report and subsequent outcomes' Research in Transportation Economics (48) 277-285

White, P and Robbins, D (2012). Long-term development of express coach services in Britain. Research in Transportation Economics (36) 30-38

White, Peter (2017) Chapter 2 'Bus Economics' in Cowie, Jonathan and Ison, Stephen, The Routledge Handbook of Transport Economics, Routledge, London and New York. 